\section{D) Check for updates}

Cite this: Polym. Chem., 2019, 10 4389

Received 30th May 2019,

Accepted 30th June 2019

DOI: 10.1039/c9py00793h

rsc.li/polymers

\title{
Photoresponsive polymers with multi-azobenzene groups
}

\author{
Shaodong Sun, ${ }^{a}$ Shuofeng Liang, ${ }^{a}$ Wen-Cong $X u^{a}$, Guofeng $X u^{* a}$ and Si Wu (D)*a,b
}

\begin{abstract}
Azobenzene is a switchable compound that exhibits reversible trans-cis photoisomerization. Photoresponsive polymers have been prepared by incorporating azobenzene groups into polymers. Most of the reported azobenzene-containing polymers (azopolymers) have only one azobenzene group in the repeat unit of the polymers (mono-azopolymers). To improve photoresponsiveness, multi-azobenzene groups have been covalently or non-covalently introduced into the repeat units of azopolymers (multi-azopolymers). In this Perspective, we introduce photoresponsive multi-azopolymers. We summarize the preparation of such polymers and highlight their potential applications in photoactuation, photo-patterning, and photoinduced birefringence. The innovative potential, open questions, and remaining challenges in this field are also discussed.
\end{abstract}

\section{Introduction}

Azobenzene is a photoswitchable compound. ${ }^{1}$ Light irradiation can induce reversible trans-to-cis isomerization. ${ }^{2,3}$ This property enables the use of light to control a variety of properties of azobenzene-containing materials, such as their

${ }^{a}$ CAS Key Laboratory of Soft Matter Chemistry, Hefei National Laboratory for Physical Sciences at the Microscale, Anhui Key Laboratory of Optoelectronic Science and Technology, Department of Polymer Science and Engineering, University of Science and Technology of China, Jinzhai Road 96, Hefei 230026, China. E-mail: gfxu@ustc.edu.cn, siwu@ustc.edu.cn

${ }^{b}$ Max Planck Institute for Polymer Research, Ackermannweg 10, 55128 Mainz, Germany.E-mail:wusi@mpip-mainz.mpg.de

Si Wu

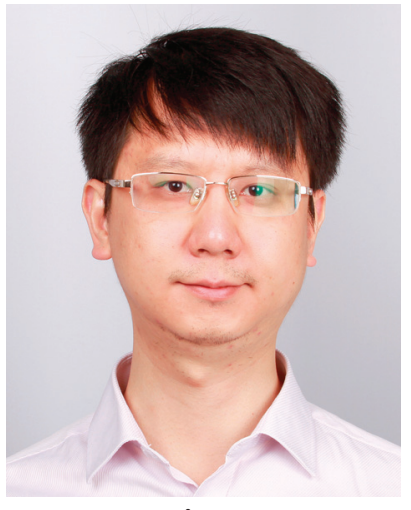

Si Wu is a full professor at the University of Science and Technology of China (USTC), Hefei, China. He studied polymer chemistry at the USTC and obtained a bachelor's degree in 2005. He was supported by the joint doctoral promotion programme working at the USTC and the Max Planck Institute for Polymer Research (MPIP), Mainz, Germany. After obtaining his PhD in 2010, he worked as a postdoctoral fellow at the MPIP and became a group leader in 2012. He headed a research group at the MPIP from 2012 to 2018. In 2018, he joined the USTC as a full professor. His research focuses on photoresponsive polymers. polarity, ${ }^{4,5}$ solubility, ${ }^{5,6}$ melting points, ${ }^{7-9}$ glass transition temperature $\left(T_{\mathrm{g}}\right)$ values, ${ }^{10-12}$ viscosity, ${ }^{13-15}$ wrinkles, ${ }^{16-18}$ morphology, ${ }^{19-23}$ mechanical properties, ${ }^{24,25}$ etc. In the past, the photophysical and photochemical properties of azobenzene derivatives have been extensively studied. Substituents strongly influence the spectral characteristics and photoswitching behaviors of azobenzene derivatives. Rau divided azobenzenes ${ }^{26,27}$ into three types (Fig. 1): (1) azobenzene-type compounds bearing alkyl, aryl, halide, carbonyl, amide, nitrile, ester, and carboxylic acid substituents. The $\pi-\pi^{*}$ and $n-\pi^{*}$ absorption bands of trans azobenzene are located in the UV range and visible range, respectively. UV irradiation induces trans-to-cis isomerization (Fig. 2a). The half-life of cis isomers is usually from hours to days. Visible light irradiation
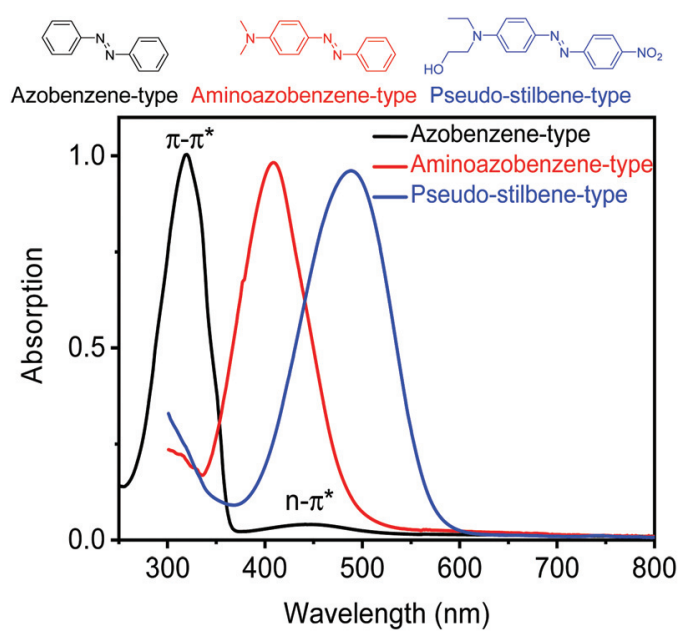

Fig. 1 Typical chemical structures and UV/Vis absorption spectra of three types of azobenzenes. 
(a)

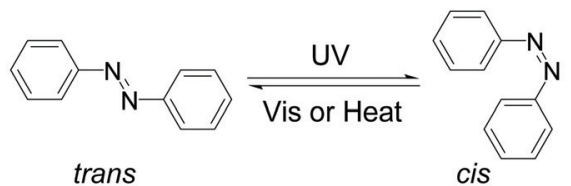<smiles>[R]c1ccc(N=Nc2ccc(N=Nc3ccccc3)cc2)cc1</smiles>

Fig. 2 (a) Photoisomerization of azobenzene and bis-azobenzene derivatives. (b) Schematic illustrations of the photoinduced orientations of azobenzene chromophores in the solid state. (c) Birefringence is induced under LPL irradiation, reaches a saturated value after irradiation for a certain time, relaxes via thermal relaxation when LPL is turned off, and is erased using CPL. (d) Formation of photoinduced SRGs. (e) Schematic illustrations of photoactuation.

(b)<smiles>[R1]c1ccc(N=Nc2ccc(N=Nc3ccc(N=Nc4ccc([R])c(N=Nc5ccc(N=Nc6ccccc6)cc5)c4)cc3)cc2)cc1</smiles>

Incident light

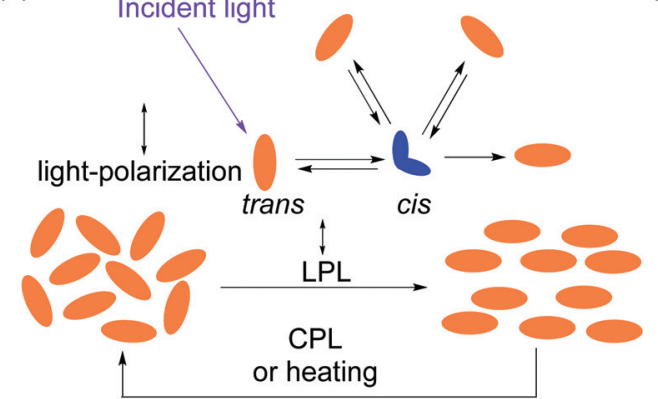

(d)

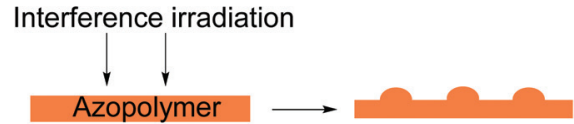

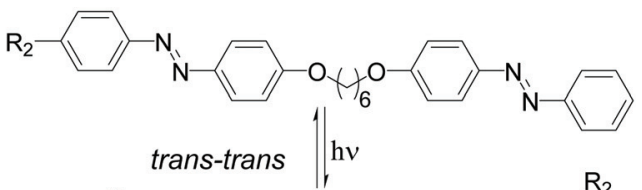

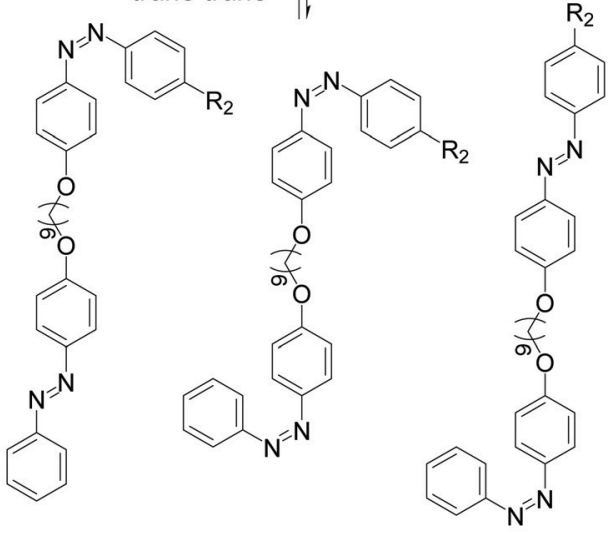

cis-trans

cis-cis

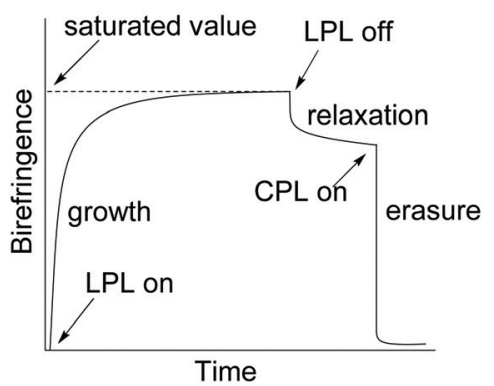

(e)
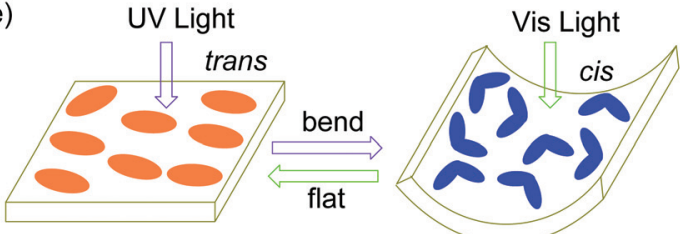

or thermal relaxation induces cis-to-trans isomerization (Fig. 2a); (2) aminoazobenzene-type compounds having at least one amino or hydroxyl group located ortho or para to the azobenzene group. The $\pi-\pi^{*}$ absorption band of the trans isomer is bathochromically shifted to $400-450 \mathrm{~nm}$, partially overlapping with the $n-\pi^{*}$ absorption band. The half-life of cis isomers becomes shorter, usually from milliseconds to seconds; (3) pseudo-stilbene-type compounds containing a push-pull substitution para to the azobenzene group. Their $\pi-\pi^{*}$ absorption band and $n-\pi^{*}$ absorption band are both located in the visible range, completely overlapping with each other. These types of azobenzene compounds have a fast rate for photoisomerization. The half-lives of cis isomers are usually from milliseconds to seconds.
All these types of azobenzene compounds have been incorporated into polymers that have better processability than small molecules. Polymers provide azobenzene group suited matrices for photoisomerization in the solid state. In addition, besides photoisomerization, ${ }^{28,29}$ azobenzene-containing polymers (azopolymers) show other interesting photoresponsive properties such as photoinduced orientation (Fig. 2b and c), ${ }^{30-43}$ formation of surface relief gratings (SRGs) (Fig. 2d) ${ }^{44-48}$ photoactuation (Fig. 2e), ${ }^{49-54}$ and photo-controlled self-assembly behaviors. ${ }^{55-66}$ When an azopolymer film is irradiated with linearly polarized light (LPL), ${ }^{67,68}$ the azobenzene groups tend to orient perpendicular to the light polarization. Subsequent circularly polarized light (CPL) irradiation or heating can erase the orientation (Fig. 2b). ${ }^{30-35}$ Thus, bire- 
(a)

(e)

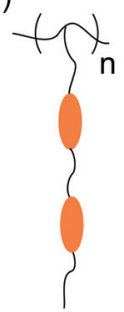

(b)

(f)

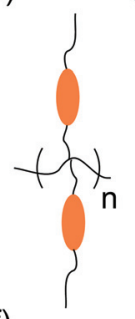

(c)

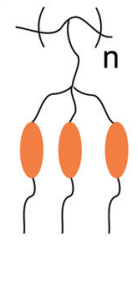

(g)
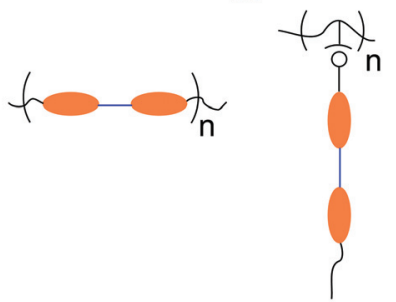

(i)

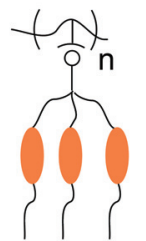

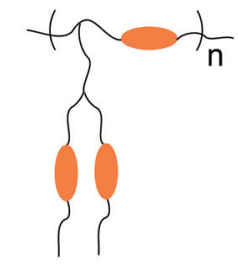

(h)

(d)

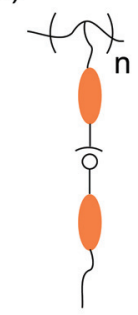

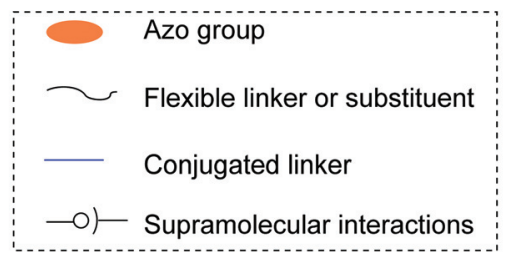

Fig. 3 Schematic illustrations of multi-azopolymers with different structures: (a-d) non-conjugated multi-azopolymers, (e and f) conjugated multi-azopolymers, and $(\mathrm{g}-\mathrm{i})$ supramolecular multi-azopolymers.

fringence can be generated and erased by light irradiation (Fig. 2c). When an azopolymer film is irradiated with interference laser beams, SRGs are induced (Fig. 2d). ${ }^{69-73}$ Another photoresponsive behavior of azopolymers is photoactuation. Light irradiation can induce macroscopic motions such as bending and contraction of azopolymers (Fig. 2e). ${ }^{74,75}$ Azopolymers can also undergo self-assembly via supramolecular interactions and light can control the physicochemical properties of supramolecular azopolymers. ${ }^{76-86}$ There are comprehensive reviews about the development of azopolymers and the investigations of photoresponsive properties mentioned above. ${ }^{67,87-89}$

Different from previous reviews, in this Perspective, we focus on azopolymers that have multi-azobenzene groups in the repeat unit. We call these types of polymers multi-azopolymers. Conventional azopolymers have only one azobenzene group in each repeat unit; such mono-azopolymers have been widely studied. The photoisomerization of multi-azobenzene groups results in more types of isomers (Fig. 2a). Multi-azobenzene groups may have a larger aspect ratio than mono-azobenzene groups, exhibiting larger birefringence when oriented. Multiazobenzene groups also exhibit interesting (liquid) crystallinities. With more azobenzene groups in a repeat unit of polymers, multi-azopolymers show some unique photoresponsive properties. ${ }^{90-92}$ Here, we present the current status of multi-azopolymers, their potential applications, and the challenges, with the aim of highlighting the most relevant literature in this field.

(a)<smiles>CCCCCCCCC(CCCCCC)C(C)OC(=O)c1ccc(N=Nc2ccc(OCCCCCCCCCCC(C)(C)OC(=O)C(CC(C)(C)C)C(C)(C)C)cc2)cc1</smiles>

(b)

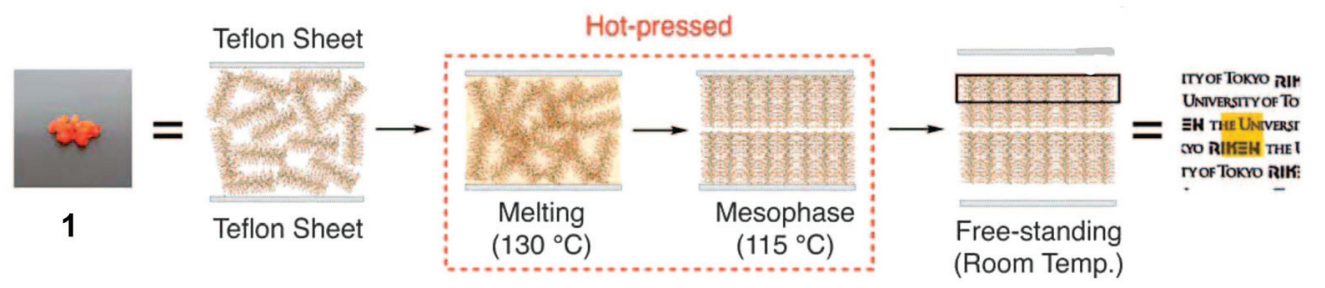

(c)

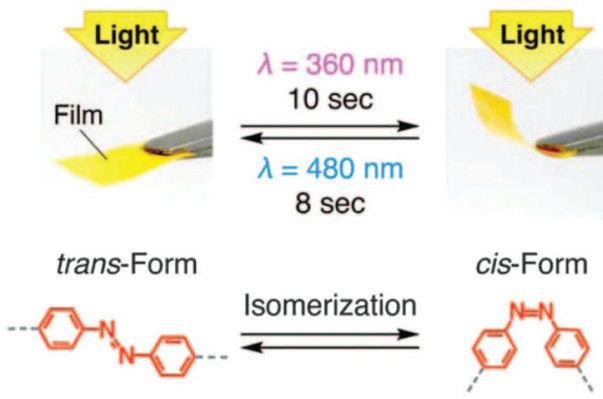

(d)

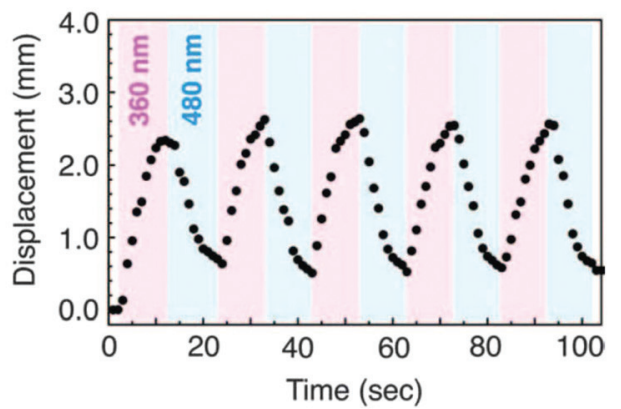

Fig. 4 (a) Chemical architectures of polymers 1 and 2. (b) Schematic illustrations of the preparation of free-standing films via hot-pressing. (c) Photographs of a hot-pressed film $(5 \mathrm{~mm} \times 6 \mathrm{~mm} \times 10 \mu \mathrm{m})$ prepared with parallel-arranged Teflon sheets before (left) and after (right) exposure to UV light $(\lambda=360 \pm 2 \mathrm{~nm})$. The bent film recovered the initial flat shape upon exposure to visible light $(\lambda=480 \pm 2 \mathrm{~nm})$. (d) Time-dependent change in the displacement of the free edge of a hot-pressed film prepared with parallel-arranged Teflon sheets upon alternating irradiation with UV and visible lights. Reproduced with permission from ref. 93, copyright 2010, AAAS. 


\section{Types of multi-azopolymers}

We summarize a few types of multi-azopolymers in Fig. 3. There is still room for designing new multi-azopolymers based on polymer chemistry, supramolecular chemistry, and organic chemistry. From the polymer chemistry point of view, multiazobenzene groups can be introduced into polymer side chains, backbones, or both. Because of the diversity of polymer structures, new multi-azopolymers can be designed. From the supramolecular chemistry point of view, multiazopolymers can be prepared by non-covalently introducing multi-azobenzene groups into polymers. From the organic chemistry point of view, small-molecule multi-azobenzene groups can have different structures (see for example bisazobenzenes with flexible and conjugated linkers in Fig. 2a). Multi-azobenzene groups can be introduced into a repeat unit of polymers either in parallel or in series. In the following, we introduce different types of multi-azopolymers according to their structures.

\section{Polymers with non-conjugated multi- azobenzene groups}

Non-conjugated azobenzene groups mean that two or more azobenzene groups are connected via non-conjugated flexible linkers. Non-conjugated multi-azobenzene groups can be introduced into polymers in series. For example, Aida and coworkers studied a polymer with three azobenzene groups in series in the side chain of each repeat unit (Fig. 4). ${ }^{93}$ They synthesized a methacrylate monomer with three azobenzene groups and prepared polymer $\mathbf{1}$ through free radical polymerization (Fig. $4 \mathrm{a}, m=3$ ). Because of the long side chains, polymer $\mathbf{1}$ is like a brush. The polymer chains of $\mathbf{1}$ were oriented homeotropically to the substrates via one-step hot-pressing (Fig. 4b). The hot-pressed film exhibited a rapid and reversible photomechanical response under the irradiation of UV and visible light (Fig. 4c and d). ${ }^{74,94}$ In contrast, the control sample, polymer 2 (Fig. $4 \mathrm{a}, m=1$ ), which had only one azobenzene group in each repeat unit, did not show the alignment behavior by hot pressing. These results indicate that the multi-azopolymer forms ordered structures more easily via hot pressing than the mono-azopolymer does. On the basis of these interesting findings, the authors demonstrated a design principle for polymers that form 2D homeotropic orders. ${ }^{95}$

Akiyama et al. prepared oligo-dendrimer type molecules, multiazobenzene sugar-alcohol derivatives, ${ }^{96-98}$ in which the multi azobenzene groups were connected in parallel with each other. These kinds of molecules showed photochemically reversible solidliquid transitions and could be applied to reworkable adhesives.

In 2013, Zhu and Wang reported polymers with two and three azobenzene groups in parallel in the polymer side chains. ${ }^{99}$ These polymers showed reversible photoisomerization. Furthermore, birefringence was induced by LPL

(a)

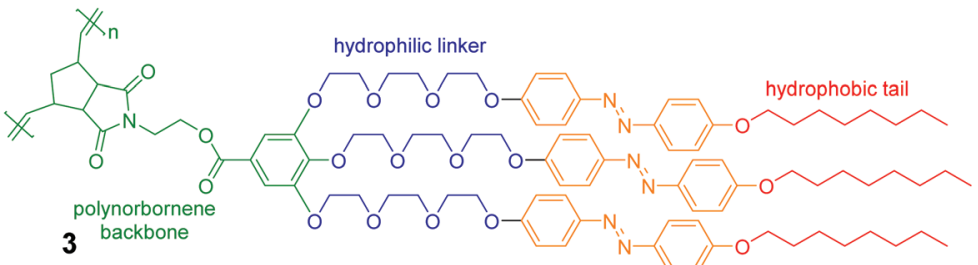

(b)

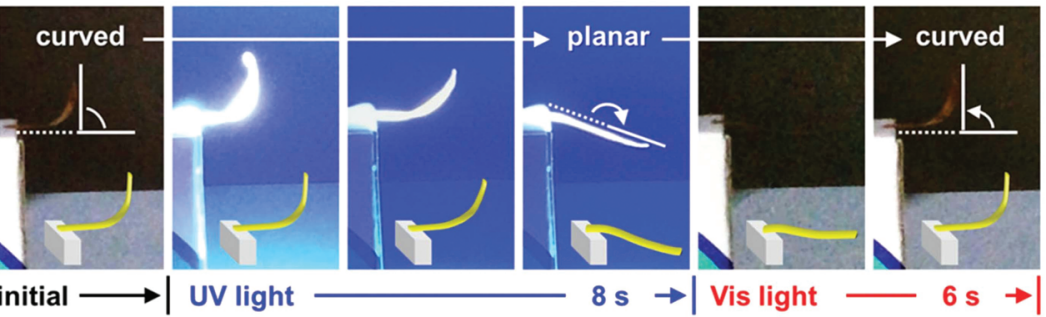

(c)

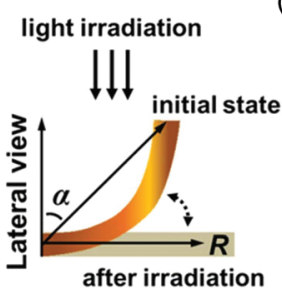

(d)

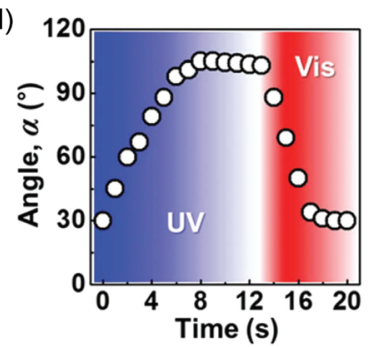

(e)

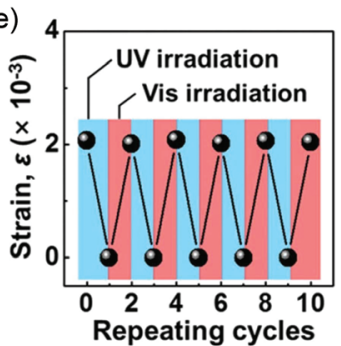

Fig. 5 (a) Chemical structure of polymer 3. (b) Photo-modulation of a freestanding film of 3 upon UV and visible light irradiation. (c) Schematic illustration of the photomechanical motion. (d) Reversible flexion angle changes with respect to UV and visible irradiation. (e) Repeated experiments of the photo-stimulated bending strain. Reproduced from ref. 100. Copyright (2017) Wiley-VCH Verlag GmbH \& Co. KGaA, Weinheim. 
irradiation. Multi-azobenzene moieties in each repeat unit of the polymer resulted in larger birefringence.

Kim et al. also prepared polymers with azobenzene groups in parallel in the polymer side chains (Fig. 5). ${ }^{100}$ Different from Zhu and Wang's strategy, polymer 3 was synthesized via ring opening metathesis polymerization (ROMP). Free-standing films were prepared. The backbone and azobenzene side chains of polymer 3 in the film were perpendicular and parallel to the layer normal, respectively. When the film was exposed to UV light, it quickly bent away from the light source due to trans-to-cis isomerization (Fig. 5b-d). After subsequent visible light irradiation, the film recovered to its original state because of cis-to-trans back isomerization. Photoinduced bending and unbending were fully reversible (Fig. 5e). Further investigations showed that such types of multi-azopolymers exhibit photoisomerization $^{101}$ and photoinduced chirality, ${ }^{102}$ and can be used as photoresponsive semiconductors with good photo-fatigue resistance. ${ }^{103}$

\section{Polymers with conjugated multi- azobenzene groups}

Some azo groups were connected via conjugated linkers. Conjugated multi-azobenzene groups have been introduced into polymer side chains (Fig. 6a). Polymer 4 was prepared by Meng and Natansohn through free radical polymerization. ${ }^{90}$ Compared with $\mathbf{5}$ that has mono-azobenzene groups (Fig. 6b), ${ }^{104} 4$ showed larger photoinduced birefringence because of the intrinsic higher aspect ratio of the bis-azobenzene group (Fig. 6c and d). In addition, 4 showed a slower rate of photoinduced birefringence and a higher birefringence stability than $\mathbf{5}$, which is because of the lower mobility of the bis-azobenzene group.

In addition, polymethacrylates with similar structures have been synthesized and their photoresponsive properties, such as photoisomerization, ${ }^{91,105-112}$ photo-alignment, ${ }^{106,107,110}$ (a)

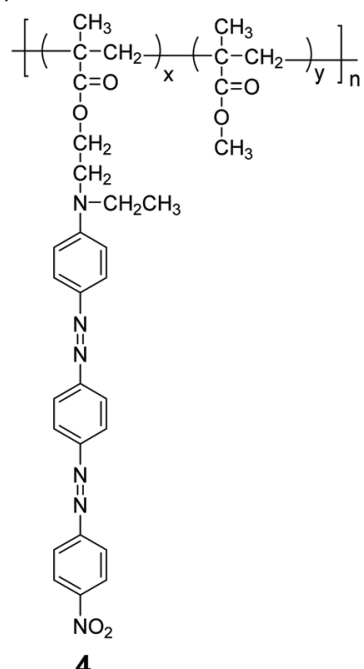

(b)

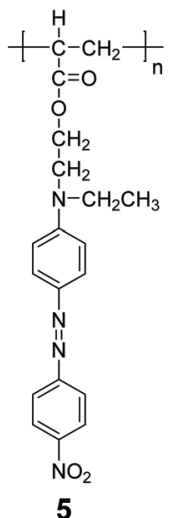

(c)

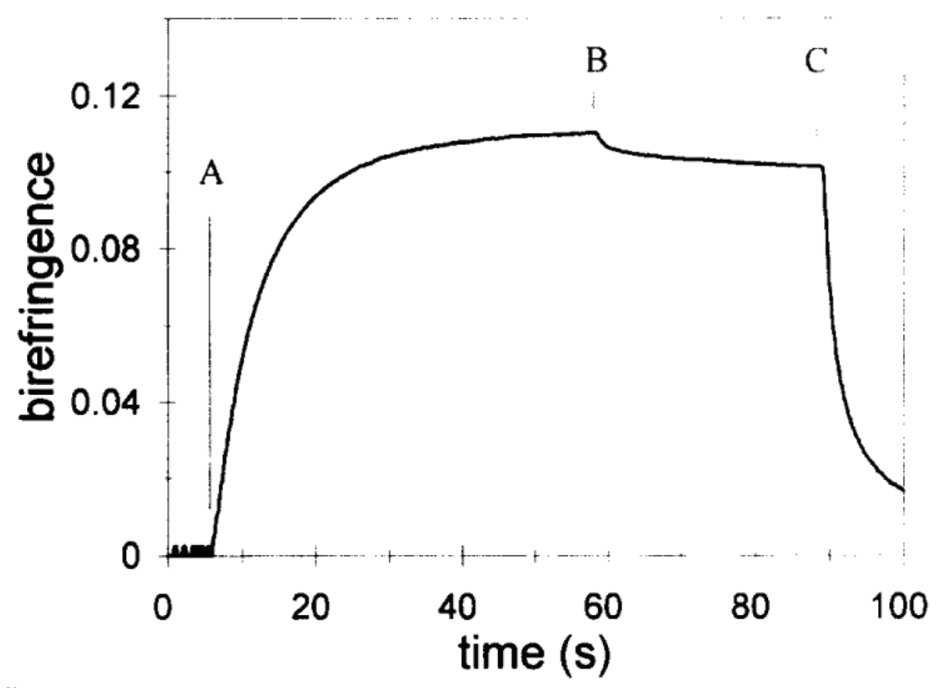

(d)

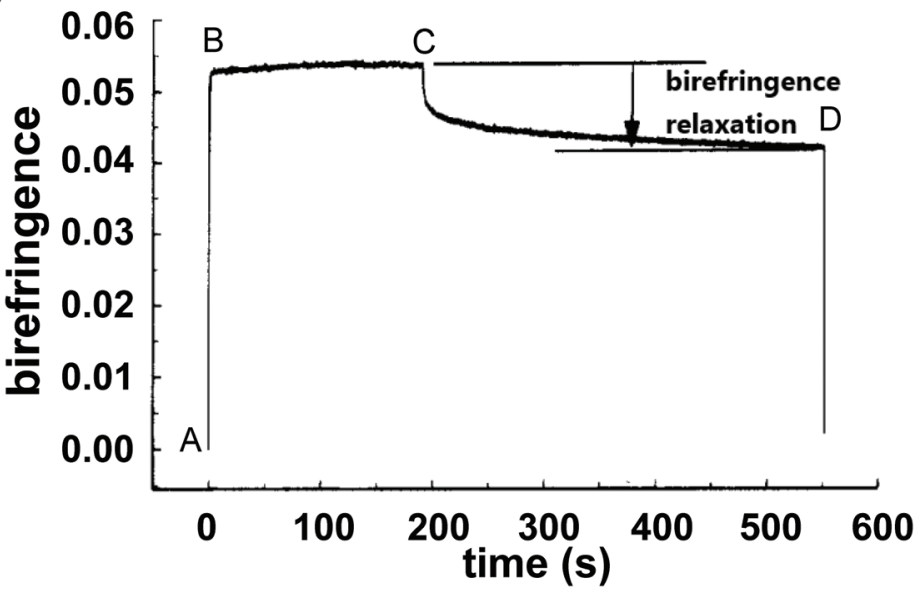

Fig. 6 Chemical structures of (a) 4 and (b) 5. Writing-erasing profile of the photoinduced birefringence of films of (c) 4 and (d) 5 . Panel (c) is reprinted from ref. 90. Copyright (1997) with permission from Elsevier. Panel (d) is reprinted with permission from ref. 104. Copyright (1995) American Chemical Society. 

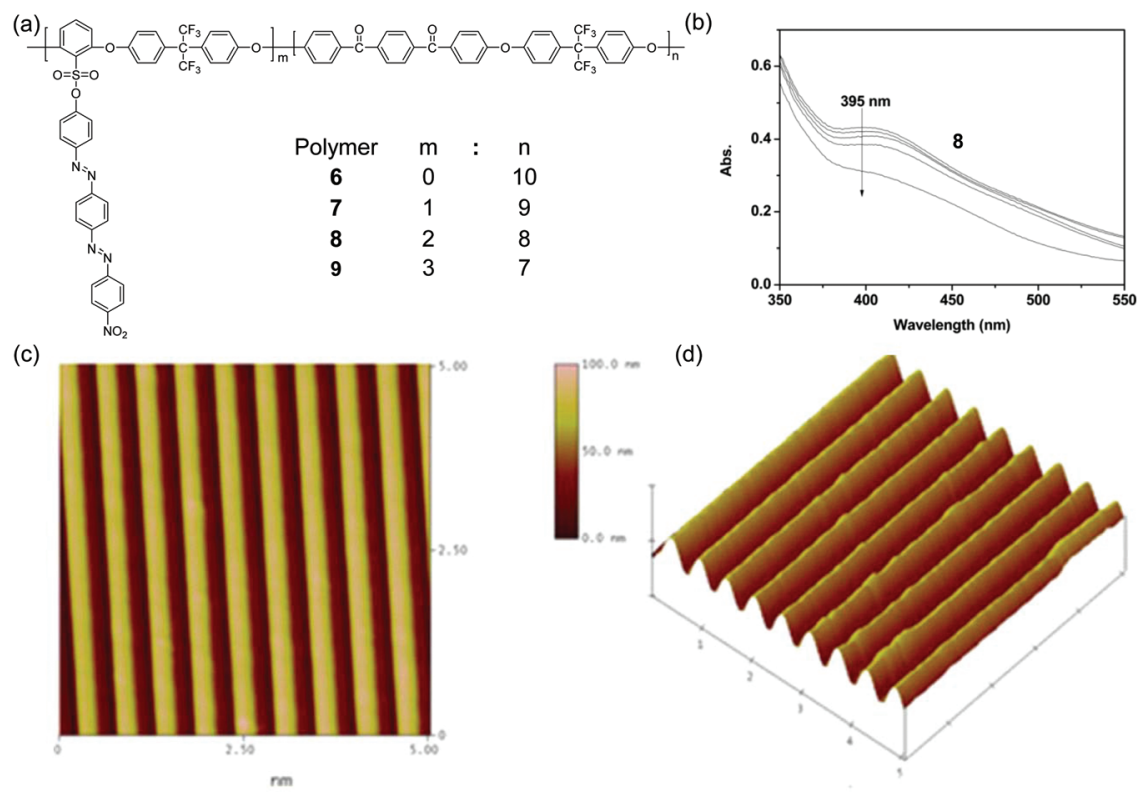

Fig. 7 (a) Chemical structures of 6, 7, 8 and 9. (b) Changes in the UV-Vis absorption spectra of 8 in DMF induced by $405 \mathrm{~nm}$ light irradiation. (c) AFM plane view of the SRGs and (d) AFM 3-D view of the SRGs. Reprinted with permission from ref. 119. Copyright (2016) SAGE Publications.

(a)

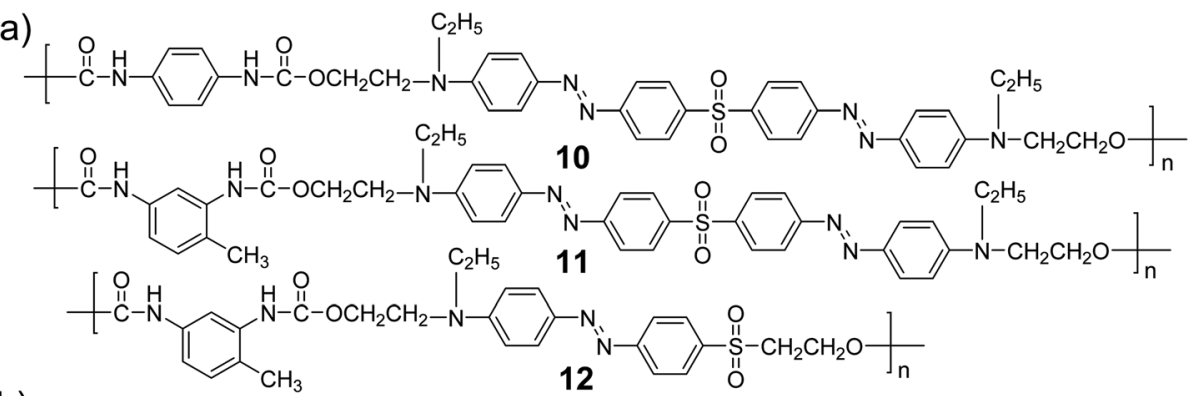

(b)

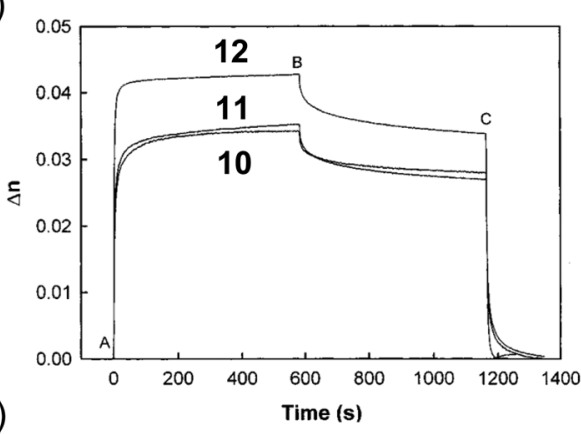

(d)

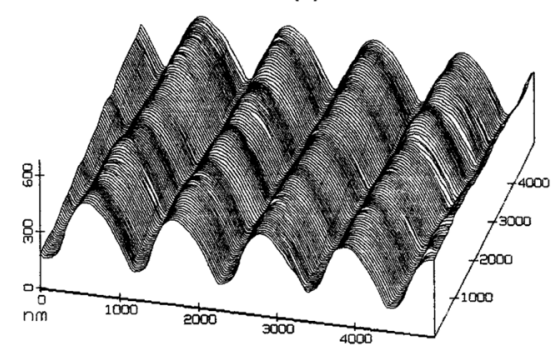

(c)

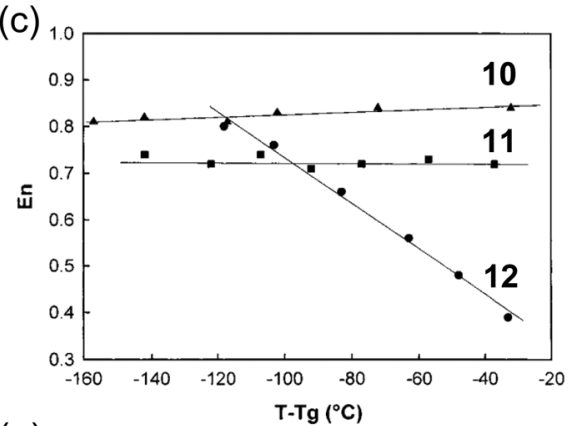

(e)

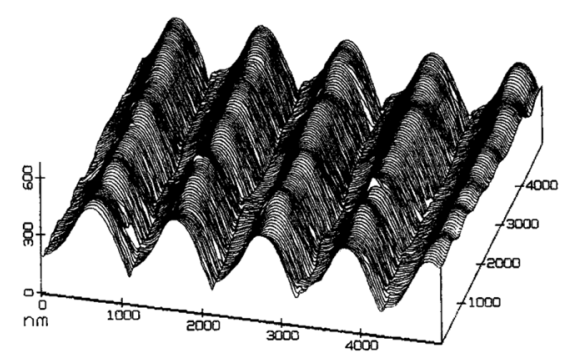

Fig. 8 (a) Chemical structures of 10, 11, and 12. (b) Typical birefringence curves for 10, 11, and 12 films. LPL is turned on at point A and turned off at point $\mathrm{B} ; \mathrm{CPL}$ is turned on at point $\mathrm{C}$. (c) Long-term stable birefringence, $E_{n}$, which is denoted as the ratio of birefringence conserved for a very long time to saturated birefringence, as a function of reduced temperature. The lines are only a guide to the eye. $\mathbf{\Lambda}, 10 ; \mathbf{\square}, 11 ; \bullet, 12$. AFM surface grating profile of 11 observed before (d) and after (e) thermal treatment at $182{ }^{\circ} \mathrm{C}$ for 90 min. Reprinted with permission from ref. 120. Copyright (2001) American Chemical Society. 
photoinduced birefringence, ${ }^{91,105,106,108-110,113}$ information storage, ${ }^{112}$ and the induction of helical chirality, ${ }^{111,114,115}$ have been investigated. The rate of photoinduced birefringence for the bis-azopolymers was slower than that for monoazopolymers, ${ }^{90,91}$ while the birefringence values for bisazopolymers were higher and the birefringence stability for bis-azopolymers was better than those for monoazopolymers. $^{90,91,108,109}$ However, there was an exception, where both the rate and the level of photoinduced birefringence for the bis-azopolymers were better than those for mono-azopolymers. ${ }^{105}$ In addition to multi-azopolymers with a poly(meth)acrylate backbone, multi-azopolymers with other types of backbones have also been studied, such as polymethacrylamides showing photoinduced birefringence ${ }^{116}$ and polyurethane anionomers showing photoisomerization. ${ }^{117}$

Besides photoinduced birefringence, multi-azopolymers are also suited for photoinduced SRGs. In an early example, Wang et al. reported the inscription of SRGs on polymers with conjugated bis-azobenzene groups on polymer side chains. ${ }^{118}$ Recently, Zhang et al. synthesized poly(aryl ether)s 6, 7, 8, and 9 (Fig. 7) via polycondensation. ${ }^{119}$ Polymers 6, 7, 8, and 9 had high glass transition temperature $\left(T_{\mathrm{g}}\right)$ values and good thermal stability. ${ }^{119}$ These polymers also showed photoisomerization (Fig. 7b) and photoinduced SRGs under the irradiation of interference beams (Fig. 7c and d), which have potential applications in optical data storage.

Besides polymers with conjugated multi-azobenzene groups on side chains, polymers with conjugated multi-azobenzene groups on polymer backbones were also reported. Wu et al. reported a series of main-chain type bis-azopolyurethanes (10 and 11) (Fig. 8). ${ }^{120}$ The mono-azopolyurethane (12) was also studied for comparison. Polymers 10, 11, and $\mathbf{1 2}$ had $T_{\mathrm{g}}$ values at $182{ }^{\circ} \mathrm{C}, 167{ }^{\circ} \mathrm{C}$, and $143{ }^{\circ} \mathrm{C}$, respectively. ${ }^{120}$ All of them showed photoinduced birefringence (Fig. 8b). Polymers 10 and 11 displayed smaller birefringence than polymer $\mathbf{1 2}$ due to the bent $\mathrm{V}$ shape of the bis-azobenzene groups that did not generate large birefringence. Wu et al. quantitatively investigated the stability of birefringence with parameter $E_{\mathrm{n}}$, where $E_{\mathrm{n}}$ is defined as the ratio of birefringence conserved for a very long time to saturated birefringence. A higher value of $E_{\mathrm{n}}$ meant higher stability. They found that the birefringence of $\mathbf{1 0}$ and 11 showed higher stability than that of $\mathbf{1 2}$ at high tempera-

\section{(a)}

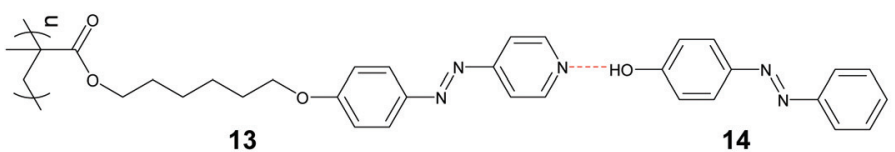

(b)

(d)
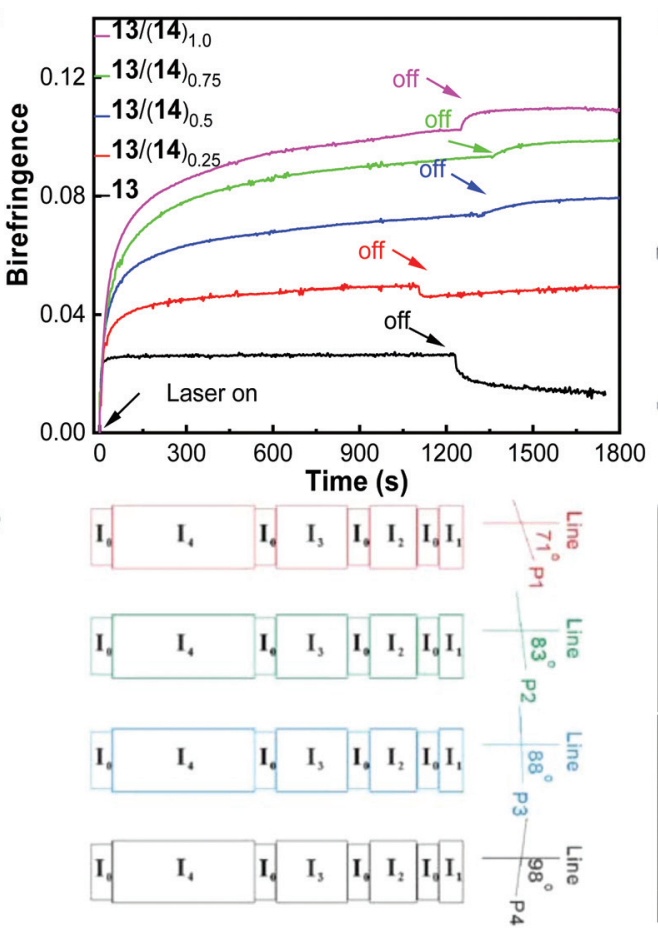

(c)
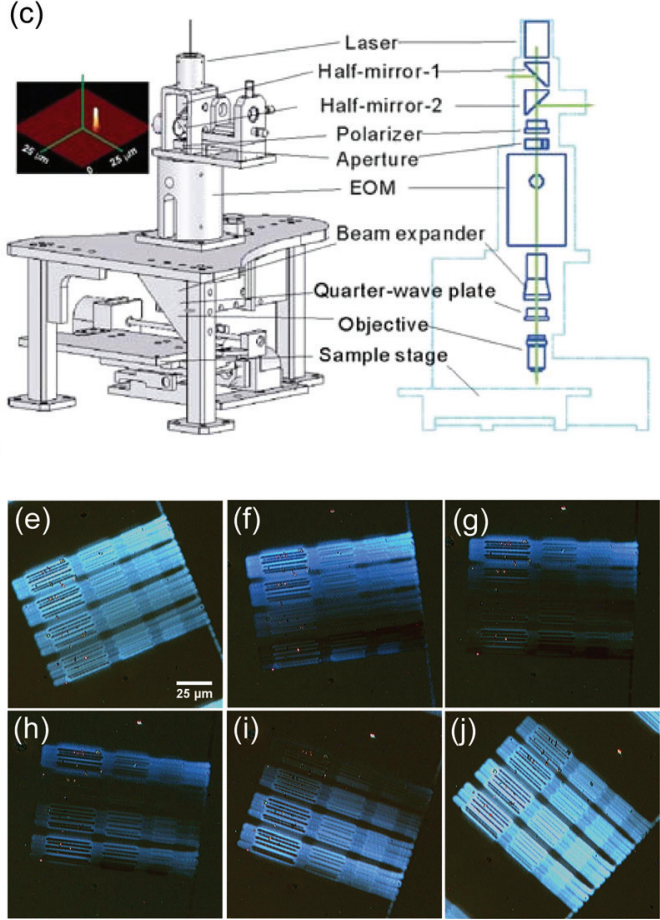

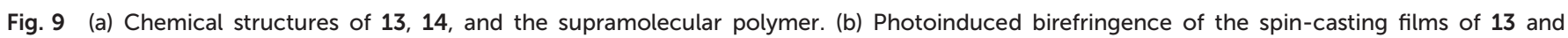

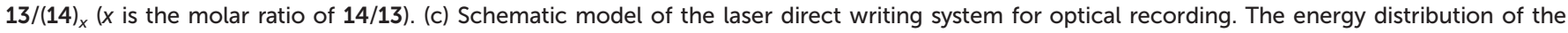

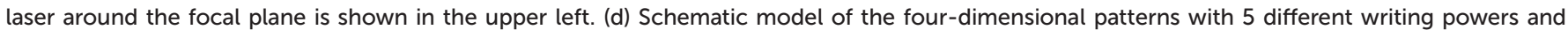

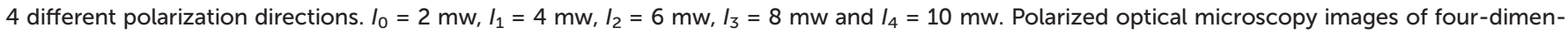

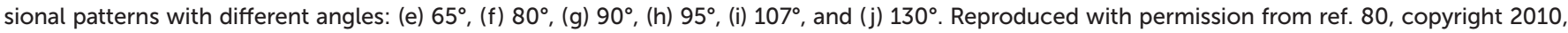
the Royal Society of Chemistry. 
tures, even close to $T_{\mathrm{g}}$ (Fig. 8c), which was attributed to the following two reasons: (1) the bulky bis-azobenzene groups with lower mobility enhanced the stability of the orientation; (2) the special architectures of V-shaped bis-azobenzene groups might result in higher relative stability of the photoinduced birefringence. The SRG formed in polymer 11 could be only partly erased by heating (Fig. $8 \mathrm{~d}$ and e), which was distinct from thermally erasable SRGs reported in other literature studies. ${ }^{121,122}$ Based on this work, the authors further investigated photoinduced birefringence and SRGs in polyurethane elastomers with bis-azobenzene groups in the hard segment. $^{123}$

Another type of main-chain conjugated multi-azopolymer, which contained azobenzene crown ether moieties, has been studied by Ardeleanu et al. ${ }^{124,125}$ This type of multi-azopolymer also showed good thermal stability and reversible photoisomerization behavior.

In addition, a novel organo-phosphonate with bisazobenzene moieties in the main chain has been reported by Homocianu et al. $^{126}$ The new structure endowed the polymers with reversible dual stimuli response, such as light and $\mathrm{pH}$.

\section{Supramolecular multi-azopolymers}

In the above two sections, multi-azobenzene groups were introduced into polymers covalently. In contrast, multi-azobenzene groups can also be introduced into polymers via supramolecular interactions. Supramolecular multi-azobenzene groups can be introduced into polymers in series or in parallel.

One of us designed supramolecular bis-azopolymers by connecting a side-chain azopolymer with azobenzene small molecules via hydrogen bonding (Fig. 9a). ${ }^{80}$ Compared with the mono-azopolymer (13, Fig. 9a), the supramolecular polymers 13(14) $)_{x}$ showed larger photoinduced birefringence and better stability when the content of $\mathbf{1 4}$ increased (Fig. 9b). These results are attributed to higher concentrations of azobenzene groups, a higher aspect ratio of the chromophores, and more ordered structures based on chromophore-chromophore interactions. In addition, by using a newly designed laser direct writing system (Fig. 9c), the supramolecular polymer 13(14) was used for four-dimensional optical recording by integrating the polarization and the intensity of the laser and the planar two dimensions (Fig. 9d), which had an information density 20 times that of a normal DVD. Fig. $9(e-j)$ show the polarized (a)

(c)
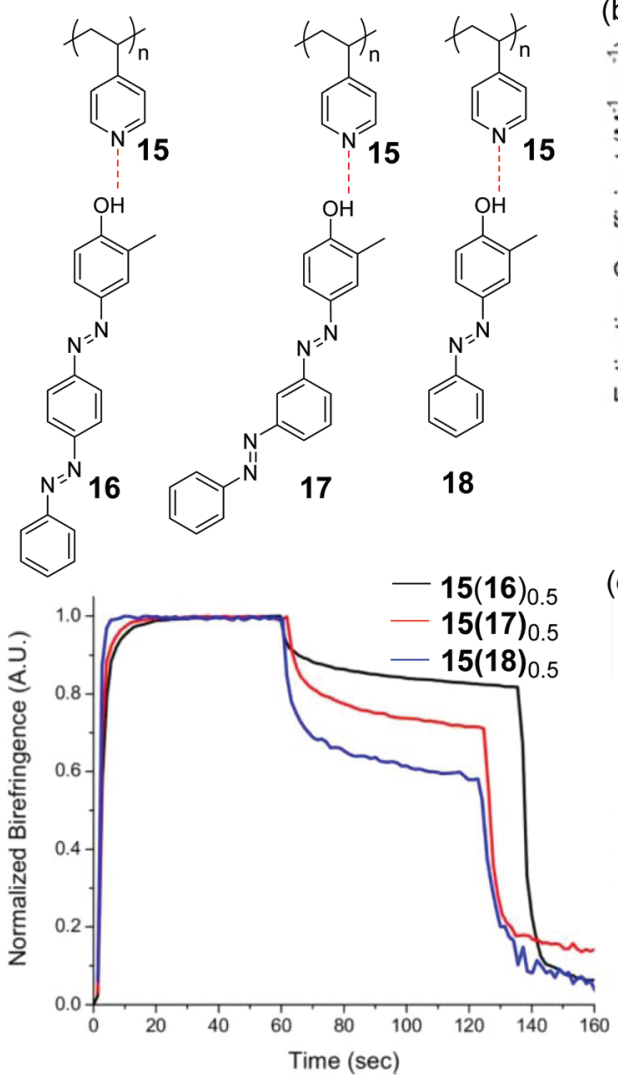

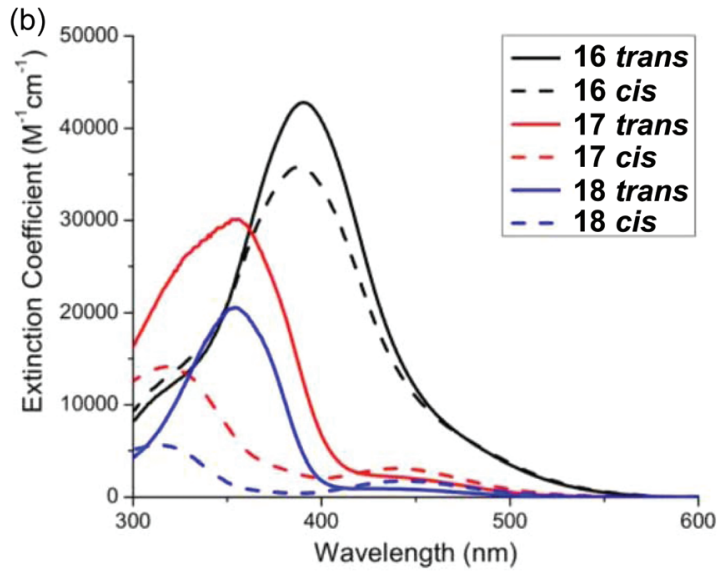

(d)

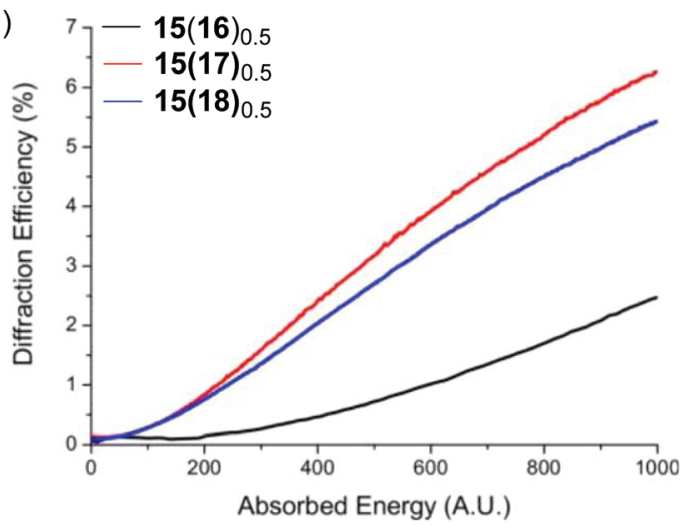

Fig. 10 (a) Chemical structures of 15, 16, 17, and 18 and hydrogen-bonded supramolecular polymers constructed using these compounds. (b) UVVis absorption spectra of 16, 17, and 18 in THF. (c) Normalized birefringence for thin films of $15(16)_{0.5}, 15(17)_{0.5}$, and $15(18)_{0.5}$ induced by $488 \mathrm{~nm}$ light, where 0.5 means the average number of azobenzene chromophores per polymer repeat unit. (d) First-order diffraction efficiencies of 15 (16) 0.5 , 15(17) 0.5 and 15(18) 0.5 during SRG inscription under $488 \mathrm{~nm}$ light irradiation as a function of absorbed energy. Reprinted with permission from ref. 92. Copyright (2014) American Chemical Society. 
optical microscopy images of the microstructure at different angles. These types of supramolecular bis-azopolymers have better solubility and processability than the covalent bisazopolymers.

Priimagi et al. reported another type of supramolecular bisazopolymer by connecting poly(4-vinylpyridine) (P4VP) with bis-azobenzene small molecules via hydrogen bonding. ${ }^{127-129}$ They prepared SRGs on the supramolecular bis-azopolymers. Furthermore, Vapaavuori et al. compared the photoresponsive properties of supramolecular polymers with bis-azobenzene and mono-azobenzene groups (Fig. 10). ${ }^{92}$ Supramolecular multi-azopolymers showed better photoinduced birefringence (Fig. 10c). Supramolecular bis-azopolymers 15(17) $)_{0.5}$ exhibited more efficient photoinduced SRG formation (Fig. 10d). A few investigations based on similar supramolecular azopolymers were reported. ${ }^{129-132}$
Besides hydrogen-bonded supramolecular multi-azopolymers, supramolecular multi-azopolymers based on other supramolecular interactions such as host-guest interactions ${ }^{133}$ and ionic interactions ${ }^{84}$ have also been investigated. These polymers formed supramolecular hydrogels with multi-stimuli responsive properties $^{133}$ and were used for photoinduced SRGs. ${ }^{84}$

The above-mentioned examples showed that supramolecular multi-azobenzene groups can be introduced into polymers in series, while del Barrio et al. demonstrated supramolecular polymers that had hydrogen-bonded multi-azobenzene groups in parallel (Fig. 11). ${ }^{134}$ The photoinduced orientations of these supramolecular multi-azopolymers were studied (Fig. 11a-c). The supramolecular multi-azopolymers showed large and stable photoinduced birefringence even at low contents of the azobenzene compounds (Fig. 11b-d), which were superior to the systems previously reported. ${ }^{135}$ Additionally, other studies based (a)

(b)

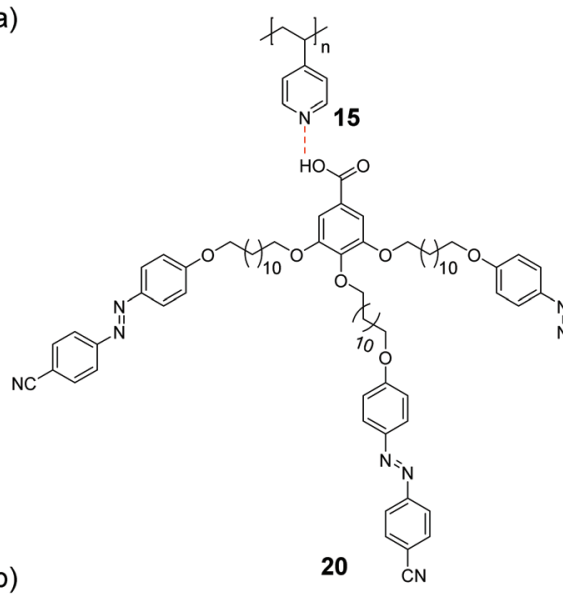$$
\text { 旁 }
$$

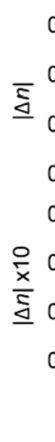

(c)

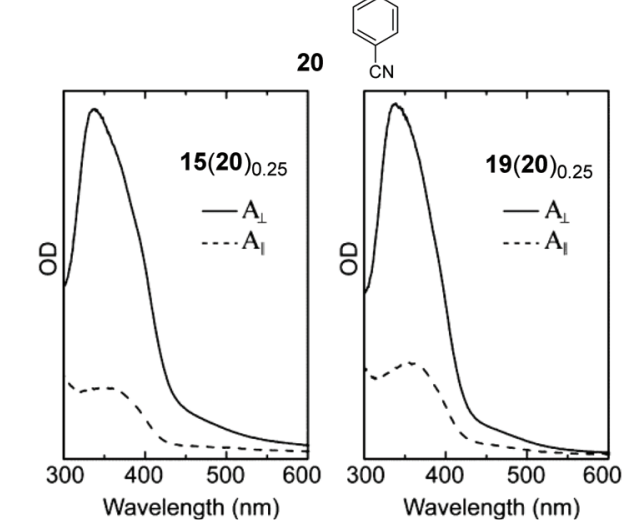

\begin{tabular}{cccc}
\hline complex & $\mathbf{x}$ & $|\Delta \mathrm{n}|_{\text {norm }} \times 10^{3}$ & dichroic ratio \\
\hline \multirow{3}{*}{$\mathbf{1 5}(\mathbf{2 0})_{\mathbf{x}}$} & 0.06 & 1.5 & 4.9 \\
& 0.12 & 1.6 & 4.9 \\
& 0.25 & 1.6 & 5.3 \\
& 0.50 & 1.6 & 5.5 \\
\hline \multirow{2}{*}{$\mathbf{1 9 ( 2 0})_{\mathbf{x}}$} & 0.06 & 0.87 & 3.2 \\
& 0.12 & 0.97 & 4.0 \\
& 0.25 & 0.94 & 3.8 \\
\hline
\end{tabular}

Fig. 11 (a) Chemical structures of 15, 19, 20, and supramolecular polymers constructed using these compounds. (b) Evolution of the photoinduced birefringence in the thermally treated films of $15(20)_{0.25}$ and $19(20)_{0.25}$ under the irradiation of $488 \mathrm{~nm} \mathrm{LPL}$ (films were irradiated between $t=0$ and $t=60 \mathrm{~min}$ ). (c) Stable polarized absorption spectra of $15(20)_{0.25}$ and $19(20)_{0.25}$ recorded at room temperature after irradiation with $488 \mathrm{~nm} \mathrm{LPL}$ for $60 \mathrm{~min}$ and subsequent evolution in the dark for $30 \mathrm{~min}$ at the same temperature. (d) Values of $|\Delta n|_{\text {norm }}$ after the irradiation and relaxation periods and the equilibrium dichroic ratio. Reprinted with permission from ref. 134. Copyright (2014) American Chemical Society. 
on hydrogen-bonded polymers with supramolecular multi-azobenzene groups in parallel have been reported. Photoinduced anisotropy, ${ }^{136}$ orientation, ${ }^{136,137}$ or birefringence ${ }^{136,137}$ and the photoinduced deformation ${ }^{138}$ of these supramolecular multi-azopolymers have been investigated.

\section{Conclusions and perspective}

We introduced multi-azopolymers that exhibit interesting photoresponsive properties. Both side-chain and main-chain multi-azopolymers have been investigated. The photoisomerization of multi-azobenzene groups resulted in more types of isomers. Because multi-azobenzene groups usually have a larger aspect ratio than mono-azobenzene groups, they exhibit larger photoinduced birefringence. Multi-azobenzene groups can be introduced into polymers via supramolecular interactions. This supramolecular strategy may simplify the route for the preparation of multi-azopolymers. ${ }^{139}$ Moreover, the composition of supramolecular complexes can be adjusted easily by changing the ratio of azobenzene components and polymer matrices.

Although multi-azopolymers have been extensively studied, we believe that the full potential of multi-azopolymers has not been realised yet. Some key areas in photoresponsive polymers remain to profit from designing multi-azopolymers. Some challenges with regard to multi-azopolymers should be addressed to take this field forward.

First, multi-azobenzene groups, especially the conjugated ones, have poorer solubility than their mono-azobenzene counterparts, which makes the synthesis and processing of multi-azopolymers more difficult. Decoupling the conjugation of multi-azobenzene groups via supramolecular interactions may improve solubility and address the issue of processing.

Second, almost all the reported multi-azopolymers have linear architectures. A field that awaits exploration is the combination of interesting photoresponsiveness of multi-azobenzene groups with a variety of polymer topologies, such as stars, branches, and dendrimers. Such a design will result in new photoresponsive polymers.

Thirdly, hydrogen bonding, host-guest interactions ${ }^{133}$ and ionic interactions ${ }^{84}$ have been used to construct supramolecular multi-azopolymers. Supramolecular multi-azopolymers constructed using other supramolecular interactions such as halogen bonding ${ }^{140,141}$ and coordination ${ }^{81-83}$ are still awaiting exploration.

Fourth, multi-azobenzene small molecules with heterogenic azobenzene groups showed orthogonal photoswitching by light with different wavelengths. ${ }^{85,142,143}$ Such heterogenic multi-azobenzene groups can be switched between more than 2 states. Multi-azopolymers with heterogenic azobenzene groups have not been explored yet and can be controlled with light of different colors.

\section{Conflicts of interest}

There are no conflicts to declare.

\section{Acknowledgements}

S. W. acknowledges the Thousand Talents Plan and the Deutsche Forschungsgemeinschaft (DFG, WU 787/2-1 and WU 787/8-1) for financial support. Open Access funding provided by the Max Planck Society.

\section{Notes and references}

1 G. S. Hartley, Nature, 1937, 140, 281.

2 Y. Wu, S. Wu, X. Tian, X. Wang, W. Wu, G. Zou and Q. Zhang, Soft Matter, 2011, 7, 716-721.

3 Y. Wu, S. Wu, G. Zou and Q. Zhang, Soft Matter, 2011, 7, 9177-9183.

4 X. Tong, G. Wang, A. Soldera and Y. Zhao, J. Phys. Chem. B, 2005, 109, 20281-20287.

5 G. S. Kumar and D. C. Neckers, Chem. Rev., 1989, 89, 1915-1925.

6 M. Irie and H. Tanaka, Macromolecules, 1983, 16, 210-214.

7 Y. Norikane, E. Uchida, S. Tanaka, K. Fujiwara, E. Koyama, R. Azumi, H. Akiyama, H. Kihara and M. Yoshida, Org. Lett., 2014, 16, 5012-5015.

8 Y. Norikane, S. Tanaka and E. Uchida, CrystEngComm, 2016, 18, 7225-7228.

9 Y. Hao, S. Huang, Y. Guo, L. Zhou, H. Hao, C. J. Barrett and H. Yu, J. Mater. Chem. C, 2019, 7, 503-508.

10 C. Appiah, G. Woltersdorf, R. A. Perez-Camargo, A. J. Muller and W. H. Binder, Eur. Polym. J., 2017, 97, 299-307.

11 H. Zhou, C. Xue, P. Weis, Y. Suzuki, S. Huang, K. Koynov, G. K. Auernhammer, R. Berger, H.-J. Butt and S. Wu, Nat. Chem., 2017, 9, 145-151.

12 W.-C. Xu, S. Sun and S. Wu, Angew. Chem., Int. Ed., 2019, 58, 9712-9740.

13 G. S. Kumar, P. Depra, K. Zhang and D. C. Neckers, Macromolecules, 1984, 17, 2463-2467.

14 G. S. Kumar, P. DePra and D. C. Neckers, Macromolecules, 1984, 17, 1912-1917.

15 M. Irie, Y. Hirano, S. Hashimoto and K. Hayashi, Macromolecules, 1981, 14, 262-267.

16 T. Takeshima, W.-Y. Liao, Y. Nagashima, K. Beppu, M. Hara, S. Nagano and T. Seki, Macromolecules, 2015, 48, 6378-6384.

17 C. Zong, Y. Zhao, H. Ji, X. Han, J. Xie, J. Wang, Y. Cao, S. Jiang and C. Lu, Angew. Chem., Int. Ed., 2016, 55, 39313935.

18 C. Zong, U. Azhar, C. Zhou, J. Wang, L. Zhang, Y. Cao, S. Zhang, S. Jiang and C. Lu, Langmuir, 2019, 35, 26012609.

19 E. Uchida, K. Sakaki, Y. Nakamura, R. Azumi, Y. Hirai, H. Akiyama, M. Yoshida and Y. Norikane, Chem. - Eur. J., 2013, 19, 17391-17397.

20 R. H. Zha, G. Vantomme, J. A. Berrocal, R. Gosens, B. de Waal, S. Meskers and E. W. Meijer, Adv. Funct. Mater., 2018, 28, 1703952. 
21 S. Wu, F. Shi, Q. Zhang and C. Bubeck, Macromolecules, 2009, 42, 4110-4117.

22 J. Huang, S. Beckemper, S. Wu, J. Shen, Q. Zhang, K. Wang and A. Gillner, Phys. Chem. Chem. Phys., 2011, 13, 16150-16158.

23 S. Wu and J. Huang, RSC Adv., 2012, 2, 12084-12087.

24 Y. Yue, Y. Norikane, R. Azumi and E. Koyama, Nat. Commun., 2018, 9, 3234.

25 E. Uchida, R. Azumi and Y. Norikane, Nat. Commun., 2015, 6, 7310.

26 H. Rau, Photochemistry and Photophysics, CRC, Boca Raton, 1990.

27 H. M. D. Bandara and S. C. Burdette, Chem. Soc. Rev., 2012, 41, 1809-1825.

28 P. Weis and S. Wu, Macromol. Rapid Commun., 2018, 39, 1700220.

29 P. Weis, D. Wang and S. Wu, Macromolecules, 2016, 49, 6368-6373.

30 D. Han, X. Tong, Y. Zhao, T. Galstian and Y. Zhao, Macromolecules, 2010, 43, 3664-3671.

31 Y. Kawashima, M. Nakagawa, T. Seki and K. Ichimura, Chem. Mater., 2002, 14, 2842-2844.

32 Y. Morikawa, S. Nagano, K. Watanabe, K. Kamata, T. Iyoda and T. Seki, Adv. Mater., 2006, 18, 883-886.

33 T. Wang, X. Li, Z. Dong, S. Huang and H. Yu, ACS Appl. Mater. Interfaces, 2017, 9, 24864-24872.

34 H. Yu, T. Iyoda and T. Ikeda, J. Am. Chem. Soc., 2006, 128, 11010-11011.

35 A. Housni, Y. Zhao and Y. Zhao, Langmuir, 2010, 26, 12366-12370.

36 S. Wu, X. Yu, J. Huang, J. Shen, Q. Yan, X. Wang, W. Wu, Y. Luo, K. Wang and Q. Zhang, J. Mater. Chem., 2008, 18, 3223-3229.

37 J. Shen, S. Wu, J. Huang, Q. Zhang and K. Wang, Thin Solid Films, 2010, 518, 2128-2133.

38 S. Wu, J. Shen, J. Huang, Y. Wu, Z. Zhang, Y. Hu, W. Wu, W. Huang, K. Wang and Q. Zhang, Polymer, 2010, 51, 1395-1403.

39 S. Fu and Y. Zhao, Macromolecules, 2015, 48, 50885098.

40 S. Nagano, Y. Koizuka, T. Murase, M. Sano, Y. Shinohara, Y. Amemiya and T. Seki, Angew. Chem., Int. Ed., 2012, 51, 5884-5888.

41 A. V. Bogdanov and A. K. Vorobiev, J. Phys. Chem. B, 2013, 117, 13936-13945.

42 M. Sailer, R. Fernández, X. Lu and C. J. Barrett, Phys. Chem. Chem. Phys., 2013, 15, 19985-19989.

43 X. Wang, J. Vapaavuori, C. G. Bazuin and C. Pellerin, Macromolecules, 2018, 51, 1077-1087.

44 P. Che, Y. He and X. Wang, Front. Chem. Eng. China, 2007, 1, 360-364.

45 P. Che, Y. He and X. Wang, Chin. J. Polym. Sci., 2012, 30, 478-486.

46 H. Yu, K. Okano, A. Shishido, T. Ikeda, K. Kamata, M. Komura and T. Iyoda, Adv. Mater., 2005, 17, 21842188.
47 X. Xue, J. Zhu, Z. Zhang, N. Zhou, Y. Tu and X. Zhu, Macromolecules, 2010, 43, 2704-2712.

48 P. Weis, W. Tian and S. Wu, Chem. - Eur. J., 2018, 24, 6494-6505.

49 J. Hu, X. Li, Y. Ni, S. Ma and H. Yu, J. Mater. Chem. C, 2018, 6, 10815-10821.

50 H. Zeng, O. M. Wani, P. Wasylczyk and A. Priimagi, Macromol. Rapid Commun., 2018, 39, 1700224.

51 K. Kumar, C. Knie, D. Bléger, M. A. Peletier, H. Friedrich, S. Hecht, D. J. Broer, M. G. Debije and A. P. Schenning, Nat. Commun., 2016, 7, 11975.

52 T. J. White and D. J. Broer, Nat. Mater., 2015, 14, 10871098.

53 Y. Yu and T. Ikeda, Angew. Chem., Int. Ed., 2006, 45, 54165418.

54 K. M. Lee, M. L. Smith, H. Koerner, N. Tabiryan, R. A. Vaia, T. J. Bunning and T. J. White, Adv. Funct. Mater., 2011, 21, 2913-2918.

55 Y. Wang, S. Lin, M. Zang, Y. Xing, X. He, J. Lin and T. Chen, Soft Matter, 2012, 8, 3131-3138.

56 Y. Xing, S. Lin, J. Lin and X. He, Chin. J. Polym. Sci., 2013, 31, 833-840.

57 X. Li, B. Li, M. He, W. Wang, T. Wang, A. Wang, J. Yu, Z. Wang, S. W. Hong, M. Byun, S. Lin, H. Yu and Z. Lin, ACS Appl. Mater. Interfaces, 2018, 10, 49614970.

58 W. Su, Y. Luo, Q. Yan, S. Wu, K. Han, Q. Zhang, Y. Gu and Y. Li, Macromol. Rapid Commun., 2007, 28, 1251-1256.

59 S. Wu, L. Niu, J. Shen, Q. Zhang and C. Bubeck, Macromolecules, 2009, 42, 362-367.

60 S. Wu, Q. Zhang and C. Bubeck, Macromolecules, 2010, 43, 6142-6151.

61 S. Wu, L. Wang, A. Kroeger, Y. Wu, Q. Zhang and C. Bubeck, Soft Matter, 2011, 7, 11535-11545.

62 S. Wu, J. Huang, S. Beckemper, A. Gillner, K. Wang and C. Bubeck, J. Mater. Chem., 2012, 22, 4989-4995.

63 D. Wang and S. Wu, Langmuir, 2016, 32, 632-636.

64 Y. Chen, S. Huang, T. Wang, Z. Dong and H. Yu, Macromolecules, 2019, 52, 1892-1898.

65 S. Huang, Y. Chen, S. Ma and H. Yu, Angew. Chem., Int. Ed., 2018, 57, 12524-12528.

66 Y. Ni, X. Li, J. Hu, S. Huang and H. Yu, Chem. Mater., 2019, 31, 3388-3394.

67 A. Natansohn and P. Rochon, Chem. Rev., 2002, 102, 41394176.

68 K. Anderle, R. Birenheide, M. Eich and J. H. Wendorff, Makromol. Chem., Rapid Commun., 1989, 10, 477-483.

69 C. J. Barrett, A. L. Natansohn and P. L. Rochon, J. Phys. Chem., 1996, 100, 8836-8842.

70 C. J. Barrett, P. L. Rochon and A. L. Natansohn, J. Chem. Phys., 1998, 109, 1505-1516.

71 J. Kumar, L. Li, X. L. Jiang, D.-Y. Kim, T. S. Lee and S. Tripathy, Appl. Phys. Lett., 1998, 72, 2096-2098.

72 S. Bian, J. M. Williams, D. Y. Kim, L. Li, S. Balasubramanian, J. Kumar and S. Tripathy, J. Appl. Phys., 1999, 86, 4498-4508. 
73 O. M. Tanchak and C. J. Barrett, Macromolecules, 2005, 38, 10566-10570.

74 T. Ikeda, J. Mamiya and Y. Yu, Angew. Chem., Int. Ed., 2007, 46, 506-528.

75 Y. Xiong, L. Zhang, P. Weis, P. Naumov and S. Wu, J. Mater. Chem. A, 2018, 6, 3361-3366.

76 S. Wu and C. Bubeck, Macromolecules, 2013, 46, 35123518.

77 Y. Zhou, D. Wang, S. Huang, G. Auernhammer, Y. He, H.-J. Butt and S. Wu, Chem. Commun., 2015, 51, 27252727.

78 Y. Xiong, Z. Chen, H. Wang, L.-M. Ackermann, M. Klapper, H.-J. Butt and S. Wu, Chem. Commun., 2016, 52, 14157-14160.

79 J. Huang, Y. Huang and S. Wu, Front. Chem. Sci. Eng., 2018, 12, 450-456.

80 S. Wu, S. Duan, Z. Lei, W. Su, Z. Zhang, K. Wang and Q. Zhang, J. Mater. Chem., 2010, 20, 5202-5209.

81 L. Cui, S. Dahmane, X. Tong, L. Zhu and Y. Zhao, Macromolecules, 2005, 38, 2076-2084.

82 S. Dahmane, A. Lasia and Y. Zhao, Macromol. Chem. Phys., 2006, 207, 1485-1491.

83 S. Dahmane and Y. Zhao, J. Appl. Polym. Sci., 2006, 102, 744-750.

84 O. Kulikovska, L. M. Goldenberg and J. Stumpe, Chem. Mater., 2007, 19, 3343-3348.

85 D. Wang, M. Wagner, A. K. Saydjari, J. Mueller, S. Winzen, H.-J. Butt and S. Wu, Chem. - Eur. J., 2017, 23, 26282634.

86 D. Wang, M. Wagner, H.-J. Butt and S. Wu, Soft Matter, 2015, 11, 7656-7662.

87 H. Yu and T. Ikeda, Adv. Mater., 2011, 23, 2149-2180.

88 S. Lee, H. S. Kang and J.-K. Park, Adv. Mater., 2012, 24, 2069-2103.

89 D. Wang and X. Wang, Prog. Polym. Sci., 2013, 38, 271301.

90 X. Meng, A. Natansohn and P. Rochon, Polymer, 1997, 38, 2677-2682.

91 L. Angiolini, T. Benelli, L. Giorgini, F. Mauriello, E. Salatelli, R. Bozio, A. Daurù and D. Pedron, Eur. Polym. J., 2007, 43, 3550-3561.

92 J. Vapaavuori, A. Goulet-Hanssens, I. T. Heikkinen, C. J. Barrett and A. Priimagi, Chem. Mater., 2014, 26, 5089-5096.

93 N. Hosono, T. Kajitani, T. Fukushima, K. Ito, S. Sasaki, M. Takata and T. Aida, Science, 2010, 330, 808-811.

94 Y. Yu, M. Nakano and T. Ikeda, Nature, 2003, 425, 145.

95 Z. Chen, Y.-T. Chan, D. Miyajima, T. Kajitani, A. Kosaka, T. Fukushima, J. M. Lobez and T. Aida, Nat. Commun., 2016, 7, 13640.

96 H. Akiyama, S. Kanazawa, M. Yoshida, H. Kihara, H. Nagai, Y. Norikane and R. Azumi, Mol. Cryst. Liq. Cryst., 2014, 604, 64-70.

97 H. Akiyama, S. Kanazawa, Y. Okuyama, M. Yoshida, H. Kihara, H. Nagai, Y. Norikane and R. Azumi, ACS Appl. Mater. Interfaces, 2014, 6, 7933-7941.
98 H. Akiyama and M. Yoshida, Adv. Mater., 2012, 24, 23532356.

99 Y. Zhu and X. Wang, Polym. Chem., 2013, 4, 5108-5118.

100 D.-Y. Kim, S. Shin, W.-J. Yoon, Y.-J. Choi, J.-K. Hwang, J.-S. Kim, C.-R. Lee, T.-L. Choi and K.-U. Jeong, Adv. Funct. Mater., 2017, 27, 1606294.

101 K. Wang, L. Yin, T. Miu, M. Liu, Y. Zhao, Y. Chen, N. Zhou, W. Zhang and X. Zhu, Mater. Chem. Front., 2018, 2, 1112-1118.

102 J. Royes, A. Nogales, T. A. Ezquerra, L. Oriol, R. M. Tejedor and M. Piñol, Polymer, 2018, 143, 58-68.

103 J. Tian, L. Fu, Z. Liu, H. Geng, Y. Sun, G. Lin, X. Zhang, G. Zhang and D. Zhang, Adv. Funct. Mater., 2019, 29, 1807176.

104 D. Brown, A. Natansohn and P. Rochon, Macromolecules, 1995, 28, 6116-6123.

105 J. Wang, L. Zhang, Y. Niu, Z. Liang, Y. Chen, Y. Huang, H. Wang and W. Lin, Polym. Int., 2003, 52, 1165-1168.

106 M. Jin, Q. X. Yang, R. Lu, T. H. Xu and Y. Y. Zhao, J. Polym. Sci., Part A: Polym. Chem., 2004, 42, 4237-4247.

107 C. Cojocariu and P. Rochon, Macromolecules, 2005, 38, 9526-9538.

108 K. Okano, O. Tsutsumi, A. Shishido and T. Ikeda, J. Am. Chem. Soc., 2006, 128, 15368-15369.

109 J. Y. Kim, T. Fukuda, D. Barada, H. Ushijima and K. Yase, presented in part at Organic Holographic Materials and Applications IV, San Diego, California, United States, September, 2006.

110 M. Jin, R. Lu, Q. X. Yang, C. Y. Bao, R. Sheng, T. H. Xu and Y. Y. Zhao, J. Polym. Sci., Part A: Polym. Chem., 2007, 45, 3460-3472.

111 Z. Zheng, L. Wang, Z. Su, J. Xu, J. Yang and Q. Zhang, J. Photochem. Photobiol., A, 2007, 185, 338-344.

112 Z. Zhang, Y. Hu, Y. Luo, Q. Zhang, W. Huang and G. Zou, Opt. Commun., 2009, 282, 3282-3285.

113 B. L. Lachut, S. A. Maier, H. A. Atwater, M. J. A. de Dood, A. Polman, R. Hagen and S. Kostromine, Adv. Mater., 2004, 16, 1746-1750.

114 L. Angiolini, T. Benelli, L. Giorgini, F. Mauriello and E. Salatelli, Macromol. Symp., 2006, 234, 68-75.

115 L. Angiolini, T. Benelli, L. Giorgini, F. Mauriello and E. Salatelli, Macromol. Chem. Phys., 2007, 208, 207-217.

116 S. Wu, F. Zeng, S. Yao, Z. Tong, W. She and D. Luo, Macromolecules, 2003, 36, 9292-9294.

117 T. Buruiana and E. C. Buruiana, J. Polym. Sci., Part A: Polym. Chem., 2004, 42, 5463-5470.

118 X. Wang, J. Yin and X. Wang, Polymer, 2011, 52, 33443356.

119 J. Zhang, H. Zhang, Q. Zhang, Z. Jiang, Q. Chen and Y. Zhang, High Perform. Polym., 2016, 28, 518-524.

120 Y. Wu, A. Natansohn and P. Rochon, Macromolecules, 2001, 34, 7822-7828.

121 D. Y. Kim, S. K. Tripathy, L. Li and J. Kumar, Appl. Phys. Lett., 1995, 66, 1166-1168.

122 P. Rochon, E. Batalla and A. Natansohn, Appl. Phys. Lett., 1995, 66, 136-138. 
123 Y. Wu, A. Natansohn and P. Rochon, Macromolecules, 2004, 37, 6090-6095.

124 R. Ardeleanu, A. Airinei, G. Sacarescu and L. Sacarescu, Eur. Polym. J., 2002, 38, 2265-2270.

125 R. Ardeleanu, N. Fifere, V. Barboiu, L. Sacarescu and A. Airinei, J. Mol. Liq., 2017, 229, 362-370.

126 M. Homocianu, D. Serbezeanu, I.-D. Carja, A. M. Macsim, T. Vlad-Bubulac and A. Airinei, RSC Adv., 2016, 6, 4998049987.

127 J. Vapaavuori, A. Priimagi and M. Kaivola, J. Mater. Chem., 2010, 20, 5260-5264.

128 A. Priimagi, M. Kaivola, M. Virkki, F. J. Rodriguez and M. Kauranen, J. Nonlinear Opt. Phys. Mater., 2010, 19, 5773.

129 J. E. Koskela, J. Vapaavuori, J. Hautala, A. Priimagi, C. F. J. Faul, M. Kaivola and R. H. A. Ras, J. Phys. Chem. C, 2012, 116, 2363-2370.

130 D. Hu, K. Chen, G. Zou and Q. Zhang, J. Polym. Res., 2012, 19, 9983.

131 L. M. Saiz, P. A. Oyanguren, M. J. Galante and I. A. Zucchi, Nanotechnology, 2014, 25, 065601.

132 L. M. Saiz, I. A. Zucchi, P. A. Oyanguren, M. J. Galante, R. C. Sanfelice, D. T. Balogh and O. N. Oliveira Jr., Opt. Mater., 2014, 37, 816-822.

133 X. Wang, J. Wang, Y. Yang, F. Yang and D. Wu, Polym. Chem., 2017, 8, 3901-3909.
134 J. del Barrio, E. Blasco, C. Toprakcioglu, A. Koutsioubas, O. A. Scherman, L. Oriol and C. Sánchez-Somolinos, Macromolecules, 2014, 47, 897-906.

135 J. del Barrio, E. Blasco, L. Oriol, R. Alcalá and C. SánchezSomolinos, J. Polym. Sci., Part A: Polym. Chem., 2013, 51, 1716-1725.

136 A. Concellón, E. Blasco, M. Piñol, L. Oriol, I. Díez, C. Berges, C. Sánchez-Somolinos and R. Alcalá, J. Polym. Sci., Part A: Polym. Chem., 2014, 52, 3173-3184.

137 A. Kozanecka-Szmigiel, J. Konieczkowska, K. Switkowski, J. Antonowicz, B. Trzebicka, D. Szmigiel and E. SchabBalcerzak, J. Photochem. Photobiol., A, 2016, 318, 114-123.

138 S. Wang, N. Zhang, X. Ge, Y. Wan, X. Li, L. Yan, Y. Xia and B. Song, Soft Matter, 2014, 10, 4833-4839.

139 M. L. Hallensleben and B. Weichart, Polym. Bull., 1989, 22, 553-556.

140 Y. Chen, H. Yu, L. Zhang, H. Yang and Y. Lu, Chem. Commun., 2014, 50, 9647-9649.

141 F. Fernandez-Palacio, M. Poutanen, M. Saccone, A. Siiskonen, G. Terraneo, G. Resnati, O. Ikkala, P. Metrangolo and A. Priimagi, Chem. Mater., 2016, 28, 8314-8321.

142 F. Zhao, L. Grubert, S. Hecht and D. Bleger, Chem. Commun., 2017, 53, 3323-3326.

143 D. Wang, F. Schellenberger, J. T. Pham, H.-J. Butt and S. Wu, Chem. Commun., 2018, 54, 3403-3406. 